\title{
Evaluating the Shared Leadership Model in Knowledge Creation among the Faculty Members of Razi University of Kermanshah (Iran)
}

\author{
Amir Hossein Mohammad Davoudi ${ }^{1, *}$, Shabnam Pajohesh ${ }^{1}$, Mohammad Javad Karamafrooz ${ }^{2}$ \\ ${ }^{1}$ Department of Education Administration, Faculty of Humanities, Saveh Branch, Islamic Azad University, Iran \\ ${ }^{2}$ Department of Educational Sciences, Kermanshah Branch, Islamic Azad University, Iran
}

Copyright $(\underset{0}{2015}$ Horizon Research Publishing All rights reserved.

\begin{abstract}
The present study performed to evaluate the shared-leadership model in knowledge creation teams among the faculty members of Kermanshah Razi University. This study performed as a descriptive-correlative one and it is an applied study in regard to research goal. The statistical society of study was including all faculty members of Razi University that totally was 360 . For determine the sample volume based on Morgan's table, 179 persons selected as study sample by a random relative-category method. The author made questionnaire used as data gathering tool in this study and it includes components such as self-leadership, team confidence, team commitment, shared-leadership and knowledge creation. The content reliability of this tool confirmed by experts and Cronbach's alpha coefficient used to obtain the reliability coefficients of any component. The obtained coefficients were $0.77,0.85,0.76,0.86$ and 0.84 respectively. The regression analysis used for analyzing the information. The following results obtained. There is a positive relation between high levels of self-leadership and high levels of team confidence. There is a positive relation between high levels of team commitment and high levels of self-leadership. There is a positive relation between high levels of team confidence and high levels of shared-leadership. There is a positive and significant relation between high levels of team commitment and high levels of shared-leadership. And finally, there is a positive and significant relation between high levels of shared-leadership and high levels of knowledge creation.
\end{abstract}

Keywords Self- Leadership, Team Trust, Team Commitment, Shared Leadership, Knowledge Creation

\section{Introduction}

Self-leadership is an important aspect of teamwork that individual confidence, individual self-efficiency and individual commitment are among its sub-components, which indirectly affect the main components of team such as team confidence and team commitment. These three components are the main dimensions that result to appearing the shared leadership in teams especially those that formed to creating the knowledge [1]. Leadership is a bidirectional relation with members that in it, communication, commitment and active personality of team members is effective in making the shared leadership. As discussed in this model, the leadership weight is scattered between all members in shared leadership and all members should be take the role of leadership [2]. The main basis of integrity in any group is the confidence accompany with commitment. Confidence, co-operation and training beside the semi-concentrated and informal structure along with current technological support can be useful and effective in human resources [3].

Self-leadership: Self-leadership in behavioral motivation theory called as cognitive assessment and originated from self-decision making theory [1]. The self-leadership is a process that results to improvement of self-motivation. The self-leadership is based on assumptions of Bendura's social cognitive theory and it is considered as a self-controlling theory [1]. The self-leadership is defined as individual talents self-management [4]. Self-leadership is a theory that originated from control [4]. Self-leadership established itself as a main component to build and pioneer in all matters. The sub-components that are needed for making the self-leadership skill have a bilateral direct relation together. Self-leadership has a bilateral and direct relation with components of emotional intelligence, optimism and mental happiness. For example, as more as the self-leadership, the mental happiness will be higher and vice versa. However, individual differences such as age, gender and culture influence the self-leadership level. In addition, the personal identities such as engineering, self-control, self-supervising and needing to individual independence affect the self-leadership level [5]. The self-leadership is goal setting, self- imagination with successful performance and it is a concentrated concept about goal setting processes and its 
pursuit [4]. The self-leadership approach is focusing on self-effect instead of hierarchical control process. It is a focus on self, self-discovery and self-developing strategy [5]. The self-leadership is one the basic components in creating the subjective and collective commitment and confidence. Based on performed studies it found that subjects who have the higher self-leadership are in high levels of science and education positions. Confidence had an effective role in tendency to knowledge sharing. Many of researchers believe that confidence can result to cooperative behavior between subjects and organizational teams and it can facilitate the effective communications[19].

TeamTurst : In Parsons' viewpoint, the confidence is the agent of making unity, stability, cohesion and order. Confidence makes this believe among people that other discard their interest for reaching a group achievement [6]. Studies that performed about technology teams show that confidence results to team efficiency. Shearing the goals, mutual confidence along with respect, clearness in roles limits and individual responsibilities result to a high level of communication in team and finally increase the team confidence [6]. Confidence is a concept that is used differently in various applications. In organizations more than anywhere, it should be care that confidence not be lost [7]. The team processing a behavior related to work in a shared manner so the team members can be success in achieve to their goals. The teamwork includes mutual associates between team members and reliance on each other for reaching the goals and in this regard, confidence has an important influence on them [7]. The group evaluations and various processing roles among team members result to a focal process that provide the possibility of integration and developing the confidence among all team members [6].

In fact by having the confidence between subjects they will have more tendency to sharing their useful knowledge with others and otherwise the knowledge sharing will not happen [19]. Confidence makes the commitment. Thus, self-leadership is a strategy in team that can make confidence and commitment in others. By developing the self-leadership between the team members, the confidence will be felt corporately [19].

Team Commitment: The team members have a shared belonging feel. Commitment is a psychic investment for reaching to team goals [8]. In this viewpoint, the commitment can make motivation and it is a unique way to perceive the values. It results to increase the available opportunities and using them to communicate with coworkers and comparing the self with them. Commitment is a type of investment for security. By attention to different ways of confidence and commitment feel, it can make the motivation potentially that in turn results to integration between efficiency, self-monitoring and less mistakes; thus personnel will be punished less. The team commitment is meaningful when team encounter with a problem and its members thing together for solving it. The absence of commitment is a problem itself. The team members that work together should be have a plane [8]. In a dynamic environment three forms of commitment is needed for team members to reach more success: 1) Commitment to each other and their success: The team consists of members that believe to commitment for reach to success. This kind of commitment needs to more promotion and changing the responsibilities and duties among the team members that in turn results to less stress and more productivity. 2) Commitment to self and team success: The glory to team and commitment is important for final success. Commitment is appeared from self-role in team. Commitment is a long time chance respect to power, unity and tendency to confidence through overtop on difficult situations because effort is considered as a value in team. 3) Commitment to organization and its goals: When a team is formed for supporting the organization and its values, the commitment will reinforce and if there is not a clear perception, commitment cannot grow. The organization commitment is alike to team commitment. [1] believe that the team values, beliefs and goals provide a basis for share-leadership. Values and beliefs make the subjects as commitment people. By sharing the organizational goals even when they have confilicts result to commitment. The scientific work needs to skilled thoughts that should be corporate in team. The sole feature of knowledge is its need to subjective leadership and commitment along with shared-leadership. There is a relation between shared-leadership and knowledge creation [1].

Shared leadership: The first literatures about shared-leadership published in 1984. These authors studied a gradual change in teaching methods based on training. The shared-leadership is defined as sharing the top positions, responsibility, job, tasks and power between two or more people. The success and shared leadership is occur when the decision making power is shared for common goal [10]. The shared-leadership increase the mutual dependency, cooperation and information exchange in team and due to this, the shared-leadership effects clearly are visible in team [10]. The shared-leadership is a general leadership and while it emphasis on leadership features but today the organization leadership is not considered restrict to one person. The structure of any organization needs to a collective leadership for team members [8]. The shared-leadership is distributing the leadership between team members [10]. There is a little literatures and research about shared-leadership. One reason is unwillingness to sharing the power [13]. The shared-leadership in management context increases the legitimacy and validity of management. The shared-leadership make an active system and results of experimentally studies show that the shared-leadership has a significant relation with team performance in different aspects. The members' need to shared-leadership is related to new and sophisticated necessities, the modern work conditions accompany with technology, and finally the interdependence patterns that accompany with coordination [11].

Knowledge Creation: The current issue in organizations is individual cooperating and adjustment between personnel 
for reach the newest knowledge with least loses and most profit to winning in competition advantage particularly in learning organizations such as universities, so it can make a success fate by it. Knowledge resuscitates the modified beliefs that are made by interactions between personnel. Knowledge creation, its sharing, developing and establishing the knowledge management in organizational process framework is necessary for organization survival [10]. The knowledge creation needs to presence of personnel that have necessary information, skills, abilities and capabilities to reach a new idea, new concepts and can share the innovation products. The knowledge sharing is a communication process that in it a part of organization should be assigned for finding the new knowledge and its transferring to production part and compilation with new technology and producing the new product. The organizing and production should be done by managing the knowledge creation, sharing, transferring and reusing the knowledge. Interest to knowledge creation is emerging in team and this needs to cooperation between teams in multi field [12]

Leading other people is difficult for anyone. But, if all team members have the needed abilities, skills and knowledge for leading each other, its result is knowledge creation. The shared-leadership is the ability and skills for integration and cooperation between team members with different experiences. The shared-leadership is an important and effective agent in knowledge creation [1].

The Research History: [15] in his study by title of "self-leadership in researching works" found that those people can be creative that have the self-adjustment and more important learned it. Discussion about self- developing, self- designing and self-measuring is a subset of self-leadership. The self-leadership is a system based on maximizing the order that is needed for reach to goals. The statistical society of present study was include $\mathrm{PhD}$ students as powerful people in science and have the self-leadership skill in their personality and they could pass the academic years and reach to their goals. [14]in their study investigated the confidence in virtual teams. Their results showed that confidence results to qualitative work of group and it is a strategy for making the students group as a dynamic group and increase their communicating interactions. One problem of virtual teams is absence of confidence to facilitate the open communicating channels that in turn encourage the team for making the more confidence. In those teams that formed newly, the confidence is challenged and familiarity with others is effective in confidence making. The confidence making is the first step to reach the team goals [14].[12] in their study by title of "knowledge sharing in projects of informational teams" investigated the experimental evidence about confidence dependency role in knowledge sharing in these teams. They explored the confidence history in 14 dimensions among 135 teams and found that confidence maintain is depend on knowledge sharing and have a positive relation with it. Also, they found that there is a positive relation between confidence and information sharing among partners. In addition, confidence is related to similar values in team and percepted proficiency among the team members.[16] in their study by title of "personnel commitment increase the team efficiency" in Pakistan considered the relation between personnel commitment in teams and team efficiency prediction in Pakistan with a sample including 65 teams in five telecom operators. They found that self confidence is related with personnel commitment and team efficiency. The personnel commitment significantly is related with team commitment and the importance perception of transformational leadership is effective in maintaining the team in organization.[11] in an exploratory study as "the shared-leadership manner in software production project teams" found that the shared-leadership is the best leadership style for establishing in an effective team that is related with leaders work particularly success leaders that affect the team outcome. And this is the only leadership style that follows the tasks and needs to parallel guidance and its promotion is difficult. Chiung Huihuang (2013) in their study in Taiwan selected 4 companies and 35 work teams as study sample and considered the shared-leadership and its relation with team learning. The data analyzing showed that: 1) The shared-leadership has a positive relation with team learning. 2) The shared-leadership has a positive and significant relation with knowledge sharing. 3) The knowledge sharing has a positive and significant relation with team learning. In addition, the team features (e.x. team size, heterogeneity) is related with shared-leadership, team learning and work teams [11].

[8]in a experimentally study by title "leadership behavior and team members commitment in encountering to decisions" considered the leadership behavior, charismatic leadership, shared-leadership and their effect on team members commitment in decision makings. They obtained interest results for instants leaders can encourage the team members to take a higher level of commitment in decision making and lower dealing with made decisions. The quality is important in decision-making. Without commitment, it cannot make the decisions executive. Those members that haven't the commitment in their or in team decisions respect to team nature cause to conflict in team. But, the significant results that these authors obtained show that leaders play an important role in personnel commitment. There is a significant and positive relation between shared-leadership style and individual commitment in decision-makings. In addition, the leader's condition is related with individual commitment in decision-makings. The more important is that the charismatic and shared-leadership styles have different effects on team members' commitment. In charismatic leadership there is a higher level of conflict [8].

Larjordy and Hosseini (2010) in a research by title of "strategies to forming the teams that facilitate the knowledge creation" investigated three components (presence of common language among organization personnel; presence of individual independence in daily tasks; variety of personnel in team) as operational strategies in forming the 
knowledge creation teams. They concluded that the first two components have a significant and positive relation with knowledge creation and the third one hasn't any effect in team.

The conceptual model that offered theoretically by,[1] investigated and analyzed in this study in a practically manner to determine whether the self-leadership in a team can make the team confidence and team commitment and whether there is a relation between self-leadership and shared-leadership. And if the shared-leadership can increase the knowledge creation and bring it to a high level or not.

\section{The Research Hypothesizes:}

H1: The high level of self-leadership has a positive and significant relation with team confidence.

H2: The high level of self-leadership has a positive and significant relation with high level of team commitment.

H3: The high level of team confidence has a positive and significant relation with high level of shared-leadership.

H4: The high level of team commitment has a positive and significant relation with high level of shared-leadership.

H5: The high level of shared-leadership has a positive and significant relation with high level of knowledge creation.

\section{The Research Methodology:}

The author made questionnaire used as data gathering tool in this study and it includes components such as self-leadership, team confidence, team commitment, shared-leadership and knowledge creation. The content reliability of this tool confirmed by experts and Cronbach's alpha coefficient used to obtain the reliability coefficients of any component. The obtained coefficients were $0.77,0.85$, $0.76,0.86$ and 0.84 respectively. The regression analysis used for analyzing the information.

The first hypothesis: The high levels of self-leadership have a positive and significant relation with team confidence. This hypothesis is consists with [15] research that implemented on Ph.D students as statistical society. This is due to similarity between our statistical society of study and general people in society. Also this hypothesis is consists with [14]because our research similar to their study performed in an educational and scientific society. In addition it is consists with[12] research although it performed experimentally. This consistency is due to similarity between society and educational and scientific sample of study. Their study as our research, performed on expert people.

The second hypothesis: The high levels of self-leadership have a positive and significant relation with high levels of team commitment.

This is consists with [8] research. This is due to similarity between statistical societies in these studies. Although their study performed experimentally but it is consists with our study. This hypothesis is consists with[16]. This consistency is due to using the similar method for data gathering and data analyzing.

The third hypothesis: The high levels of team confidence have a positive and significant relation with high levels of self-leadership.

This is consists with research. This is due to similarity between statistical societies in these studies. Although their study performed experimentally but it is consists with our study. In addition, it is consists with Affan [11] research although their study performed by a different method. However, due to similarity between these studies in regard to statistical society, they are consists together.

The forth hypothesis: The high levels of team commitment have a positive and significant relation with high levels of shared-leadership.

This is consists with [8] research due to statistical society similarity. Although their study performed experimentally but their study is consists with our research. Out study is consists with[10] although their statistical society was different with our. However, they investigated the educational environment as us. In addition, this hypothesis is consists with [11] due to use a similar statistical society although their method was different. This hypothesis also is consists with [16] because in both studies a similar method used for data gathering and data analysis.

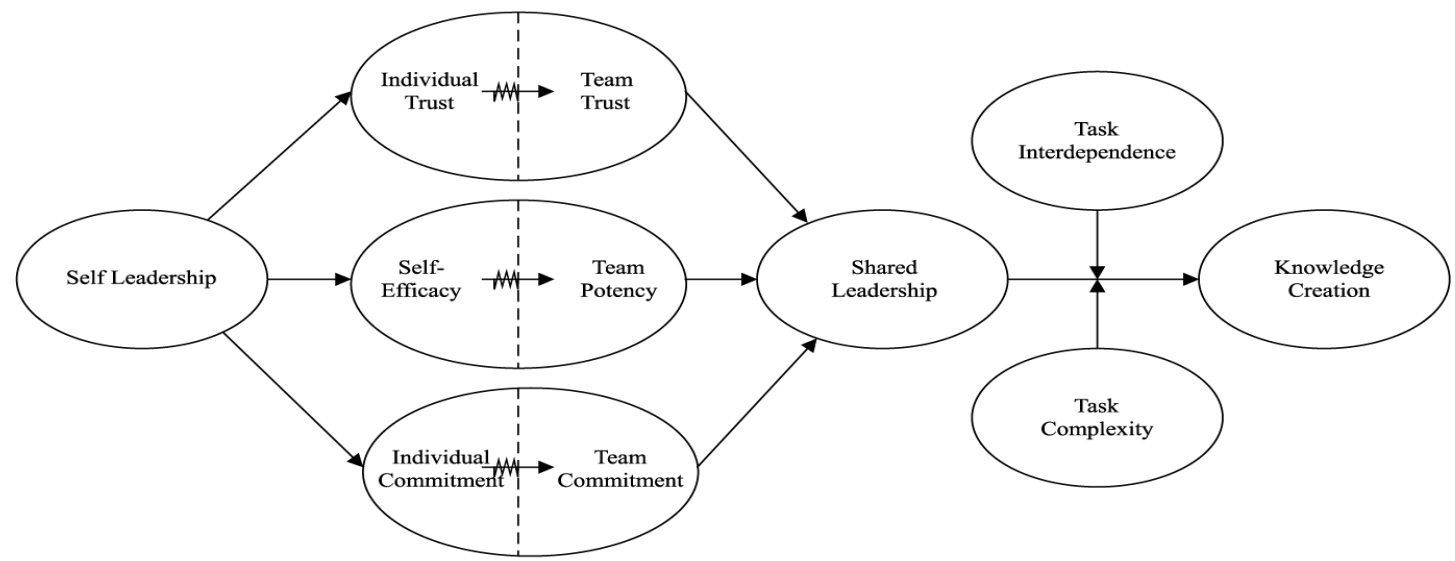

Model 1. An conceptual model for evaluating the shared-leadership in knowledge creation team that offered by Bligh, Pearce and Kohles (2006), and investigated by Mohammad Davodi et al (2014) among faculty members of Kermanshah Razi University. 
The fifth hypothesis: The high levels of shared leadership have a positive and significant relation with high levels of knowledge creation.

This is consists with research [8]due to similar statistical society although they used an experimental method. In addition, it is consists with [10]although their statistical society was different with our. However, they investigated the educational environment as us. In addition, this hypothesis is consists with [11] research due to use a similar statistical society although their method was different. This hypothesis also is consists with [12] research although their study performed experimentally but they used an educational and scientific society and investigated the expert people as what we did. This hypothesis is consists with [18] research due to similar statistical society.

It wasn't find any study against our results.

\section{Materials and Methods}

This is an applied research concerning purpose and due to investigating the current situation of model, has a descriptive method and by given the relations between model components it tries to discover the correlation between variables and predicts their relations. The statistical society of study includes all faculty members of Kermanshah Razi University during 2013 that totally are 360 people. By using the Morgan's table, 179 persons selected as the study sample through a relative stratified randomly method. The author made questionnaire used as data gathering tool in this study, which consists of 47 questions that measured by Likert's five points scale. These questions compiled after studying the research literature and theoretical framework of questions. After validation of primary questionnaire reliability by experts, it tested in a statistical society including 30 people to remove any possible incomplete or obscure question.

\subsection{Statistical Analysis}

\subsubsection{Hypothesis 1:}

There is a positive and significant relationship between high levels of self-leadership and team confidence.

The Pearson's correlation test used to determine the relation between these variables. The determinants table and regression coefficients used for predicting the changes of team confidence variable through self-leadership. Predict changes team

\subsubsection{Hypothesis 2:}

There is a positive and significant relation between high levels of self-leadership and high levels of team commitment.

For testing this hypothesis, the Pearson's correlation test used and its rate predicted as follow:

\subsubsection{Hypothesis 3:}

There is a significant and positive relation between high levels of team confidence and high levels of shared-leadership.

For testing this hypothesis, the Pearson's correlation test used and its rate predicted as follow:

\subsubsection{Hypothesis 4:}

The high levels of team commitment have a positive and significant relation with high levels of shared- leadership.

The Pearson's correlation test used for testing and predicting this hypothesis and following equation obtained for this:

\subsubsection{Hypothesis 5:}

The high levels of shared-leadership have a positive and significant relation with high levels of knowledge creation.

The Pearson's correlation test used for testing and predicting this hypothesis and following equation obtained for this:

Based on table 1 the variables of self-leadership and team confidence are significant in 0.01 level $(r=0.414, p=0.01)$ and for predicting the team confidence rate through the self-leadership, the following formula obtained:

(Self-leadership) X $0.45+12.49 \mathrm{Y}=$ (team confidence)

Table 1. The general determinants of regression analysis and coefficients of self-leadership and team confidence

\begin{tabular}{|c|c|c|c|c|c|}
\hline Statistical Indicators & Not standardize coefficients & Standard error & Standardized beta & $\mathrm{T}$ & Significance level \\
\hline Constant coefficient & 12.49 & 2.04 & - & 6.13 & 0.00 \\
\hline Self-leadership & 0.45 & 0.08 & 0.414 & 6.05 & 0.00 \\
\hline
\end{tabular}

Table 2. General determinants of regression analysis and coefficients of self-leadership and team commitment

\begin{tabular}{|c|c|c|c|c|c|}
\hline Statistical Indicators & Correlation coefficient (R) & $\mathrm{R}^{2}$ & Adjusted $\mathrm{R}^{2}$ & $\mathrm{~F}$ & Significance level \\
\hline 1 & 0.201 & 0.041 & 0.035 & 7.488 & 0.007 \\
\hline Statistical Indicator & Not standardized coefficients & Standard error & Standardized beta & $\mathrm{T}$ & Significance level \\
\hline Constant coefficient & 16.98 & 1.85 & - & 9.18 & 0.000 \\
\hline Self-leadership & 0.19 & 0.07 & 0.201 & 2.74 & 0.007 \\
\hline
\end{tabular}

Based on table 2 the correlation between two variables of self-leadership and team commitment is significant in 0.01 level $(\mathrm{r}=0.201, \mathrm{p}=0.01)$. It can use the following regression equation for predicting the team commitment rate based on selfleadership: 
(Self-leadership) X $0.19+16.98 \mathrm{Y}=$ (team commitment)

Table 3. General determinants of regression analysis and coefficients of team confidence and shared-leadership

\begin{tabular}{|c|c|c|c|c|c|}
\hline Statistical Indicators & Correlation coefficient (R) & $\mathrm{R}^{2}$ & Adjusted $\mathrm{R}^{2}$ & $\mathrm{~F}$ & Significance level \\
\hline 1 & 0.308 & 0.090 & 0.035 & 18.596 & 0.000 \\
\hline Statistical Indicator & Not standardized coefficients & Standard error & Standardized beta & $\mathrm{T}$ & Significance level \\
\hline Constant coefficient & 13.92 & 1.62 & - & 8.61 & 0.000 \\
\hline Team trust & 0.28 & 0.07 & 0.31 & 4.31 & 0.000 \\
\hline
\end{tabular}

Based on table 3 the correlation between variables of team confidence and shared-leadership is significant in 0.01 level $(\mathrm{r}=0.308,0.01)$. The following regression equation used for predicting the shared-leadership rate based on team confidence:

(Team confidence) $\mathrm{X} 0.28+13.92 \mathrm{Y}=$ (shared leadership)

Table 4. General determinants of regression analysis for team commitment and shared-leadership

\begin{tabular}{|c|c|c|c|c|c|}
\hline Statistical Indicators & Correlation coefficient (R) & $\mathrm{R}^{2}$ & Adjusted $\mathrm{R}^{2}$ & $\mathrm{~F}$ & Significance level \\
\hline 1 & 0.387 & 0.149 & 0.145 & 31.101 & 0.000 \\
\hline Statistical Indicators & Not standardized coefficients & Standard error & Standardized beta & $\mathrm{T}$ & Significance level \\
\hline Constant coefficient & 16.98 & 1.65 & - & 7.08 & 0.000 \\
\hline Team commitment & 0.41 & 0.07 & 0.39 & 5.58 & 0.000 \\
\hline
\end{tabular}

Based on table 4 the correlation between variables of team commitment and shared-leadership is significant in 0.01 level $(\mathrm{r}=0.387, \mathrm{p}=0.01)$. It can use the following regression equation for predicting the shared-leadership rate based on team commitment:

(Team commitment) $\mathrm{X} 0.28+13.92 \mathrm{Y}=$ (shared leadership)

Table5. General determinants of regression analysis and coefficients of shared leadership and knowledge creation

\begin{tabular}{|c|c|c|c|c|c|}
\hline Statistical Indicators & Correlation coefficient (R) & $\mathrm{R}^{2}$ & Adjusted $\mathrm{R}^{2}$ & $\mathrm{~F}$ & Significance level \\
\hline 1 & 0.537 & 0.289 & 0.285 & 71.784 & 0.000 \\
\hline Statistical Indicator & Not standardized coefficients & Standard error & Standardized beta & $\mathrm{T}$ & Significance level \\
\hline Constant coefficient & 8.13 & 1.41 & - & 5.76 & 0.000 \\
\hline Shared leadership & 0.57 & 0.07 & 0.31 & 4.31 & 0.000 \\
\hline
\end{tabular}

Based on table 5, the correlation between two variables of shared-leadership and knowledge creation in level 0.01 is significant ( $\mathrm{r}=0.537, \mathrm{p}=0.01$ ). The following regression equation can be set to predict the knowledge creation based on shared leadership:

(Shared leadership) $\mathrm{X} 0.57+8.13 \mathrm{Y}=$ (knowledge creation)

\section{Discussion and Conclusion}

In this research, we investigated the teamwork dimensions along with shared leadership approach and we considered the common leadership model in knowledge creation team among faculties of Razi University of Kermanshah by aim of familiarity with developing and promoting the team learning in collegiate teams and other dimensions of science making teams. All hypothesizes confirmed and it found that individuals' self- managing with individual confidence, individual commitment and self-efficiency can affect the team confidence, commitment and team power directly or indirectly. There is a direct relation between forming the team confidence and team commitment with shared-leadership. Also, the shared leadership in team related to knowledge creation. The new point in this research is the shared responsibility in team members' learning. The unison and solidarity, results the stability and believe to confidence. Based on gathered information and questionnaires about self-leadership and sub-components of self-control and self-confidence, we found that there is a direct relation between individual capabilities and problem-solving ability and these are among the key factors in team self-confidence and team power. A theoretical conceptual model designed [1]. We investigated its applicability in university environment by aim that 
understand any of these components how much is used among university faculties and how much these components are related to each other. In this regard, all of these relations except duty-dependence and complexity simultaneous with shared leadership and knowledge making established and verified. The result of this study was that for having a successful team it should be focus on individual components and individual traits. Some traits such as individual self-efficiency, individual commitment, individual confidence and self-adjustment can make an effective team. This study assessed the shared-leadership model in knowledge creation among Razi University faculty members in Kermanshah to familiarity with, promote and develop the team learning among collegiate teams with other aspects of the production team. All hypothesizes was confirmed and if found that self-leadership directly is related by team commitment and confidence; team confidence and commitment is related by shared commitment and shared-leadership in team is related by knowledge creation. Our findings are consist with other studies such as: [15] in Canada; [14] Study examines the confidence in virtual teams; [12] study of shared knowledge; [16] in research on the commitment of staff that increases the effectiveness of the team; [10]in Taiwan to study shared leadership and team learning deals; [11] in study exploratory as how the arm's joint leadership in teams; [8] in research dissertation leadership behavior and commitment of team members decisions in face of a pilot study to investigate the behavior of the leadership of the charismatic leader, shared leadership and their impact on commitment of the team members in the decision-making; [18] in research about the strategy of formation the facilitator's knowledge creation teams; and [17] in research about critical reflection on the collective knowledge interaction and reflection middle managers of a government agency to assess the individual learning process and the dynamics of social interaction payment and showed that individual learning potential has a significant effect on knowledge creation. It wasn't any research in contrary to our findings.

\section{REFERENCES}

[1] Bligh, Michelle C. ؛ Pearce, Craig L.؛ Kohles, Jeffrey C،The importance of self- and shared leadership in team based knowledge work. Journal of Managerial Psychology. 2006

[2] Dowling، Laura J ؛ Noonan، Brian. A Model for Shared Team Leadership in the Middle School Setting. APA4MSW.htm‘2002

[3] Fu Jeng Don Jyh- \& Dunk Nicolas.2013. KNOWLEDGE MANAGEMENT ENABLERS AND KNOWLEDGE CREATION IN ERP SYSTEM SUCCESS.International Journal of Electronic Business Management, Vol. 11, No. 1, pp. 49-59 49.2013

[4] Carmeli، Abraham\& Meitar، Ravit\& Weisberg، Jacob. Self-leadership skills and innovative behavior at work. www.emeraldinsight.com/0143-7720.htm.2006

[5] D’Intino، Robert S.؛ Goldsby، Michael G.؛ Houghton، Jeffery D\& Neck ‘Christopher P. Self-Leadership. A Process for Entrepreneurial Success. Journal of Leadership and Organizational Studies2007

[6] Shrestha Ayush B. \& Bernardi Richard A. \& Bosco Susan M. The Propensity to Trust Others: Gender and Country Differences. Published by Sciedu Press. ISSN 1927-5986 E-ISSN 1927-5994 .2013

[7] Hernndez، Ana؛ Zornoza، Ana؛ Virginia Orengo\&Pearroja، Vicente.. The effects of vitality level on task-related collaborative behaviors: The mediating role of team trust. Contents lists available at SciVerse

ScienceDirect.journalhomepage:www.elsevier.com/locate/co mphumbeh .2013

[8] Ng، Peggy؛ Kotlyar Igor\&, Karakowsky Leonard\&.. Leader behaviors, conflict and member commitment to team-generated decisions. Journal homepage: www. e lsevi e r.com/locate. 2011

[9] Eikenberry.Kevin .http://www.eyesonsales.com/author/kevin eikenberry/

[10] Hui Huang, Chiung . Shared Leadership and Team Learning: Roles of Knowledge Sharing and Team Characteristics. The Journal of International Management Studies, Volume 8 Number 1, Apri. 2013

[11] Yasin` Affan ؛ Yasin، Atif .2013. How Shared Leadership can be introduced in a Software Project Team? An Exploratory Study. International Journal of Scientific \& Engineering Research, Volume 4, Issue 5, May ISSN 2229-5518

[12] Park Jun-Gi \& LeeJungwoo.2013 .Knowledge sharing in information systems development projects: Explicating the role of dependence and trust. International Journal of Project Management. Available online at www.sciencedirect.com

[13] Lam Tak، Ming .2012. The influence of team trust, potency and leadership on the intent to share knowledge and team creativity. Southern Cross University, Lismore, NSW

[14] Tseng 'Hung Wei \& Te Yeh ، Hsin. Team members' perceptions of online teamwork learning experiences and building teamwork trust: A qualitative study. Journal homepage: www.elsevier.com/locate/compedu . 2013

[15] KUCUKELBIR، ALP. Embracing Self-Leadership in Early Career Academic Research. Engineering Leadership Review Preprints@http://lot.utoronto.ca/elr Posted 1127.2012

[16] Altaf ‘Asma\& Haider، Naqvi Imran. 2013. Employee Commitment Enhances Team Efficacy: Empirical Evidence on Telecom Sector of Pakistan (Lahore). World Applied Sciences Journal 22 (8): 1044-1049, .ISSN 1818-4952.2013

[17] Pandit، Gayatri \&Hamilton ، Booz Allen. Critica Reflection in Collective knowledge Creation: A mixed-method Case Study of middle Managhrs' Reflection and interaction IA public Organization. Critical Reflection in Collective Knowledge Creation..2013

[18] Lajordy, Jalil, Hosseini, Mehdi. In 2010. The strategy of facilitating knowledge creation. Strategic management studies. Summer. No. 2. Pp. 127-144

[19] Asal Aghaz, Fahimeh Negintaj, 2012; “intra organizational confidence: a key factor in real knowledge sharing"; the 

Members of Razi University of Kermanshah (Iran)

seasonal journal of Iran Management Science; 7th year, No

28, p67-86. 